\title{
A heatstroke prediction and prevention system for outdoor construction workers
}

\author{
Nobuyoshi Yabuki $^{{ }^{*}}$, Takuya Onoue ${ }^{2}$, Tomohiro Fukuda ${ }^{1}$ and Shinji Yoshida ${ }^{3}$
}

\begin{abstract}
Background: Recently, the number of heatstroke cases is increasing among construction workers. To prevent heatstroke at construction sites, it is necessary to accurately predict both the thermal environment of construction sites and the physiological condition of workers, which is presently difficult to achieve.

Methods: We have therefore developed the Construction Workers' Heatstroke Prevention (CWHP) system specifically for outdoor construction workers. The CWHP system consists of the Thermal Environment Prediction (TEP) system, which predicts changes in the thermal environment based on forecast values obtained from the Japan Meteorological Agency and results of computational fluid dynamics and solar insolation simulations, and the Core Body Temperature Prediction (CBTP) system, which predicts changes in worker core body temperature based on the TEP system results. The CWHP's heatstroke risk notification system indicates the risk of worker heatstroke considering the work site and schedule, so that construction managers can appropriately schedule work or install appropriate facilities such as tents, electric fans, and cold water tanks before work starts. The system is flexible enough to accommodate situations differing from meteorological agency forecasts.
\end{abstract}

Results: In summer 2011 the CWHP system was applied at Osaka University campus under hypothetical situations using the Virtual Reality Avatar Thermal Environment (VRATE) system, previously developed by the authors.

Conclusions: The system accurately predicted the time history of construction worker core body temperatures and informed users of times of heatstroke risk, allowing work sites and worker schedules to be modified such that new plans showed no risk for that day.

Keywords: Heatstroke; Computational fluid dynamics; Construction worker; VR; Thermal environment; Core body temperature

\section{Background}

In recent years, heatstroke has become a serious problem in summer in Japan, where the annual number of heatstroke cases has exceeded 20,000 since 2006, and is increasing yearly. In 2010 Japan experienced an extreme heat wave, during which heatstroke resulted in 56,064 hospitalizations and 1,718 deaths (Ministry of Health, Labor and Welfare MHLW 2011). Heatstroke occurs when the body temperature rises abnormally because of high temperature and humidity. About $70 \%$ of occupational heatstroke fatalities occur in the construction industry. It is well known that to prevent heat-related illnesses workers should drink plenty of water, rest

\footnotetext{
* Correspondence: yabuki@see.eng.osaka-u.ac.jp

${ }^{1}$ Division of Sustainable Energy and Environmental Engineering, Osaka

University, 2-1 Yamadaoka, Suita 565-0871, Japan

Full list of author information is available at the end of the article
}

frequently in shaded or air-conditioned areas, and wear protective clothing that provides cooling (Occupational Safety and Health Administration OSHA 2011). Once a worker indicates symptoms of heatstroke, immediate medical assistance should be requested, the worker should be moved to a cool, shaded area, and excess clothing should be removed and cool water should be applied to the body (National Institute for Occupational Safety and Health NIOSH 2010). However, as a construction site is a severe thermal environment in summer, risk of heatstroke should be evaluated considering the thermal environment and human physiology.

The construction industry has problems with health and safety (Paton 2009), and a number of studies have examined ways to improve the health and safety situations (Hastle et al. 2009, McDonald et al. 2009, Sacks et al. 2009). 
The application of virtual reality and $3 \mathrm{D}$ models to health and safety problems, especially to falls from height, has been explored by a number of researchers (Dawood et al. 2012, Zhang et al. 2013), as has research on heat stress in construction and work environments (Yi and Chan 2013, Ashraf and Naseem 2003, Tien et al. 2011). Computational Fluid Dynamics (CFD) analysis has been used extensively to simulate the thermal environment of spaces such as rooms, offices, buildings, urban areas, and global areas. Various studies have used CFD analysis to interpret and mitigate urban heat island phenomena (Ashie et al. 2007, Jiang and Hoyano 2008).

The risk of heatstroke becomes high when the core body temperature rises to about $39^{\circ} \mathrm{C}$. Equations for estimating core body temperature, described in the next section, have been proposed by Kubota et al. (2003). To evaluate risks of heatstroke in the thermal environment, wet bulb globe temperature (WBGT) is often used (Dang et al. 2006). WBGT is a composite of natural wetbulb temperature, globe thermometer temperature, and dry-bulb temperature. However, heatstroke onset depends largely on the physiological condition of the individual. Wearable thermal sensors can measure body temperature and heat rate, but failure to check sensor readings or ignoring alarms can lead to failure of such measures to prevent heatstroke. Moreover, environmental factors such as air temperature, humidity, and solar radiation significantly vary from place to place.

The authors aim to develop an individualized core body temperature prediction method for construction workers based on physiological conditions and chronological work schedule. Predictions of high risk of heatstroke would then allow work schedules to be modified beforehand. This research focuses on outdoor construction workers. To develop such a system, therefore, the thermal environment of the construction site and its surrounding area should be predicted thoroughly by the CFD analysis, and the core body temperature of each worker should be computed by the predicted thermal environment data and the individual worker's physiological condition. Furthermore, this process should be executed quickly, because a series of re-computations may be needed when heatstroke risk is identified and rescheduling is necessary. Since CFD analysis usually takes hours or even days, a new method that more quickly predicts the thermal environment is needed. In addition, the actual thermal environment may significantly deviate from computations and predictions due to climate change. Real time monitoring of the thermal environment is therefore necessary to evaluate differences from the predicted data.

No methods have been developed that satisfy these requirements. The objective of this research is therefore to develop a heatstroke prevention system for outdoor construction workers using and integrating information and communication technology and simulation technologies.

\section{Methods}

\section{Construction Workers' heatstroke prevention system}

This section describes the Construction Workers' Heatstroke Prevention (CWHP) system. This system predicts the thermal environment of a construction site and the core body temperature of site workers, thereby predicting the heatstroke risk for that day.

\section{Overview of the CWHP system}

The CWHP system is composed of three subsystems: the thermal environment prediction (TEP) system, the core body temperature prediction (CBTP) system, and the heatstroke risk notification system (Figure 1).

In the TEP system, thermal environmental data at the construction site are obtained from sensors, and JMA daily forecasts regarding local high and low temperatures and barometric patterns are obtained via the Internet. Thermal environment changes are strongly related to pressure patterns, so the TEP system predicts site temperatures based on statistical patterns in local monitoring data from the Automated Meteorological Data Acquisition System (AMEDAS) of the Japan Meteorological Agency (JMA).

The CBTP system next predicts changes in the core body temperature of each construction worker, based on individual physiological data and the thermal environment data predicted by the TEP system. The risk of heatstroke is evaluated according to core body temperature.

Finally, the heatstroke risk notification system reports when and where construction workers will experience heatstroke risk, allowing site construction managers to change work sites and daily schedules as appropriate.

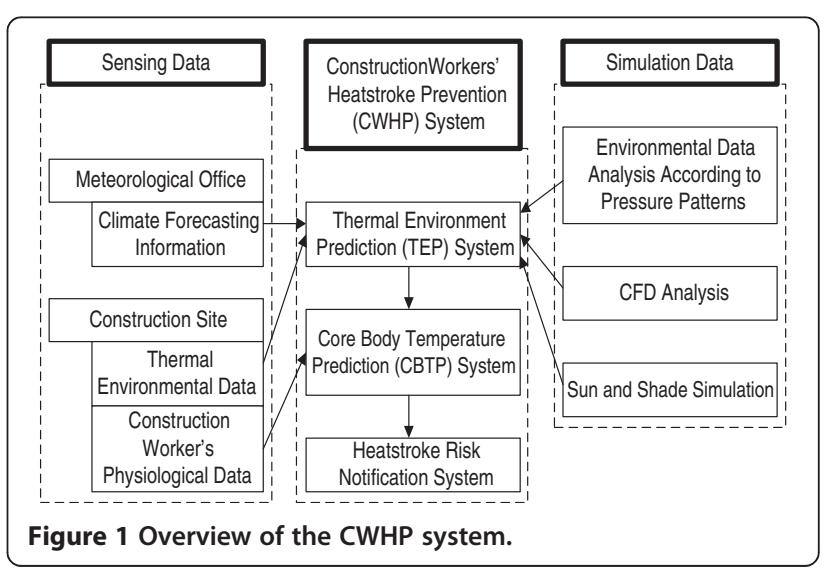




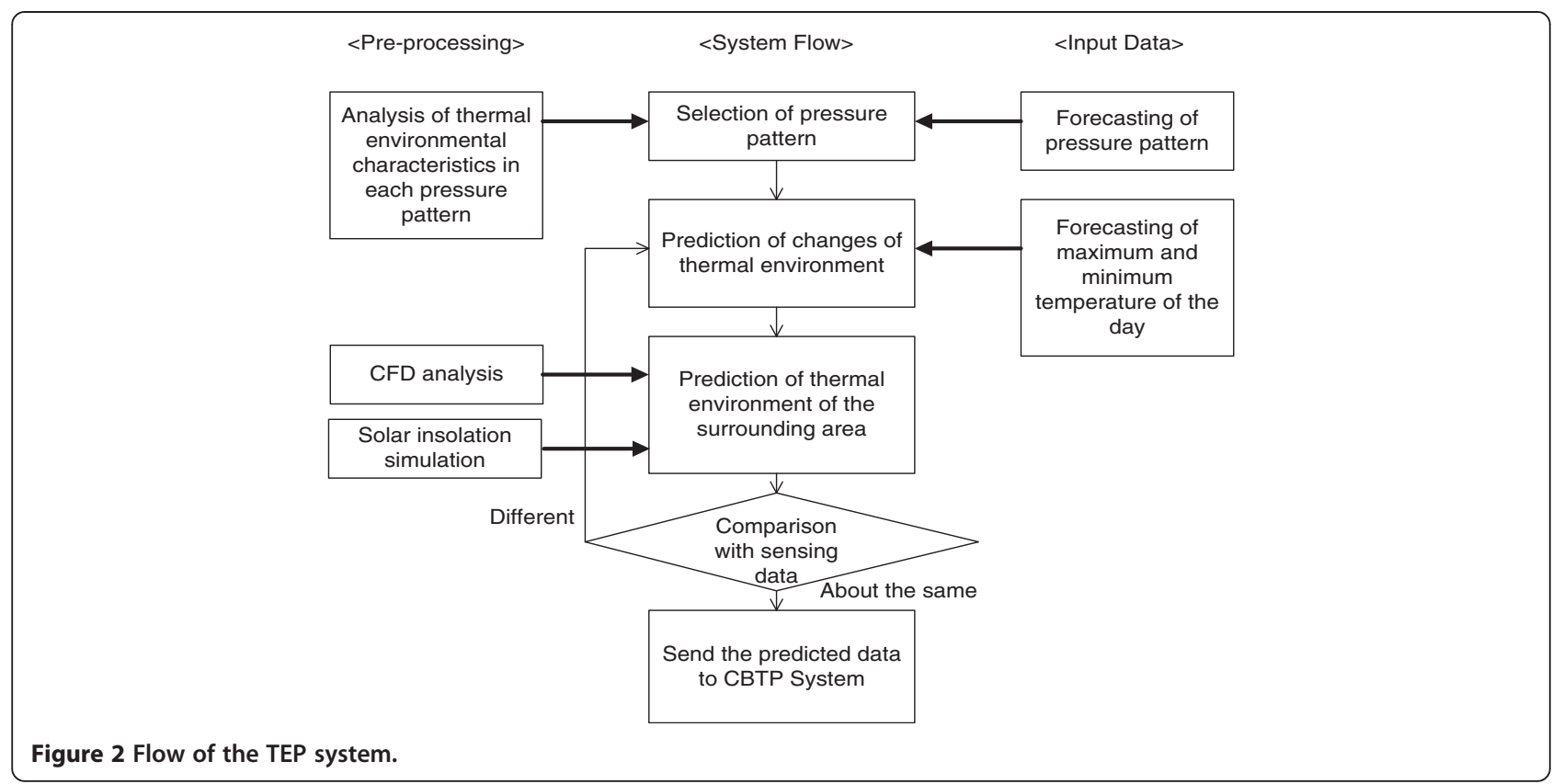

\section{Thermal environmental prediction system}

To estimate the risk of heatstroke it is necessary to forecast changes in the thermal environment, including temperature, humidity, wind direction, wind velocity, and insolation for several hours. Predicted thermal environmental data can then be used to calculate body heat loads. However, since CFD analysis usually takes from hours to days, a much faster system should be developed to predict thermal environment change. We thus propose a method for quickly predicting construction site thermal environments by developing the TEP system, which can forecast the thermal environment based factors such as barometric pressure patterns and local sensing data.

The system first selects the day's barometric pressure pattern based on the JMA forecast, then uses the day's forecasted high and low temperatures to predict changes in the thermal environment at the construction site according to prepared statistical analyses (Figure 2). The local thermal environment is predicted by a number of site CFD analysis results. Key thermal environmental data predictions and monitored values are compared, and if significant differences are identified, thermal environment predictions are modified. Otherwise, the system sends predicted environmental data to the CBTP system.

Pressure pattern selection Thermal environment changes are strongly related to pressure patterns, so the TEP system predicts site temperatures based on statistical patterns in local monitoring data from the JMA's AMEDAS. The TEP system uses statistical analysis to classify barometric pressure patterns obtained from the JMA into summer, front, unsettled, or typhoon types (Table 1). For each pressure pattern, typical charts of temperature, humidity, wind directions, wind velocity, and insolation are made. AMEDAS data for Osaka City obtained in August for years from 2006 through 2010 were analyzed to develop the system. The numbers of samples by pattern are as follows: summer, 92; front, 19; unsettled, 29; and typhoon, 16.

Figure 3 shows average time-series data and standard deviations for temperature, humidity, wind velocity, and global solar radiation. Summer pattern temperatures are higher than for other pressure types at all times and reach maximums between 13:00 and 14:00. Temperatures in the unsettled pattern are low in the morning and show large deviations. Temperatures in the front and typhoon patterns are relatively constant. Summer and unsettled humidity varies from $50 \%$ to $60 \%$ during the day, and reaches minimums between 13:00 and 14:00. Wind velocities in the summer, unsettled, and front

Table 1 Pressure patterns and their characteristics

\begin{tabular}{ll}
\hline Pressure pattern & Characteristics \\
\hline 1) Summer type & $\begin{array}{l}\text { Country is covered by a Pacific Ocean high } \\
\text { pressure system and fine, humid weather } \\
\text { continues. }\end{array}$ \\
\begin{tabular}{ll} 
2) Front type & Rain and clouds due to the front \\
3) Unsettled & $\begin{array}{l}\text { High and low pressure systems come and go } \\
\text { frequently and abrupt climate changes occur. }\end{array}$ \\
4) Typhoon type & $\begin{array}{l}\text { Heavy rain and strong wind are expected due to } \\
\text { the typhoon. }\end{array}$ \\
\hline
\end{tabular} \\
\end{tabular}




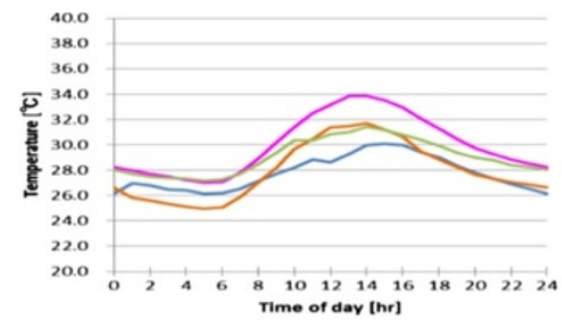

(1) Average temperature curves for pressure patterns

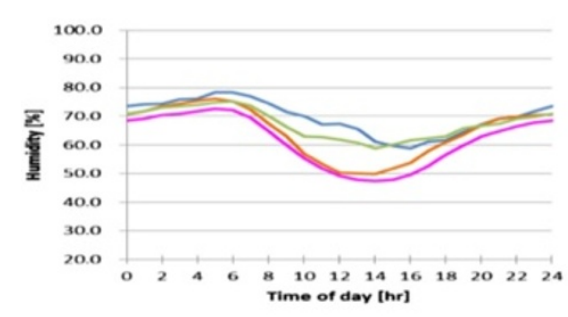

(3) Average humidity curves for pressure patterns

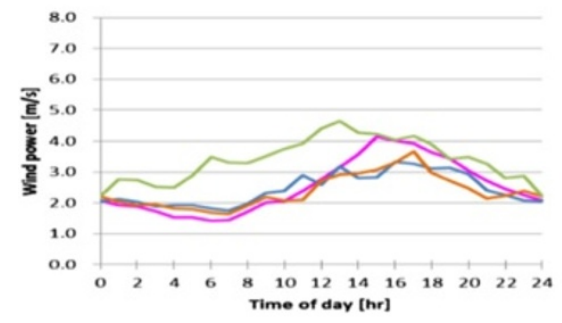

(5) Average wind velocity curves for pressure patterns

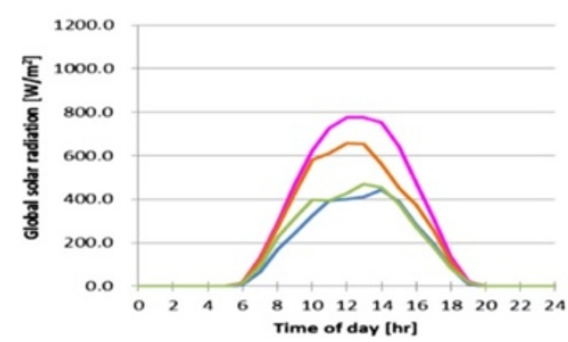

(7) Global solar radiation curves for pressure patterns

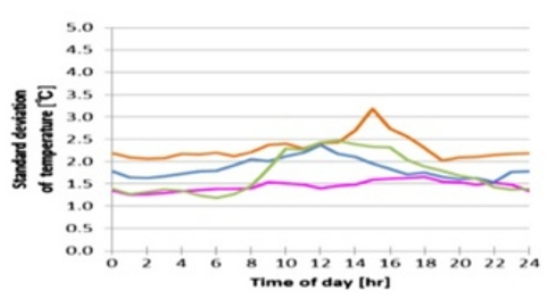

(2) Standard deviation curves of temperature

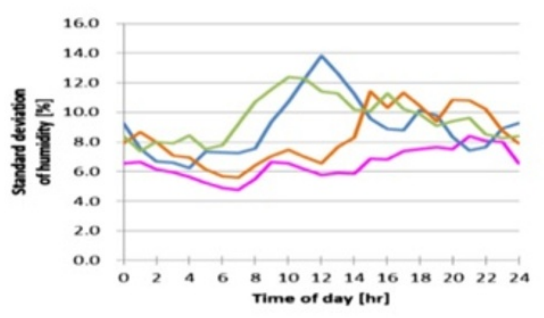

(4) Standard deviation curves of humidity

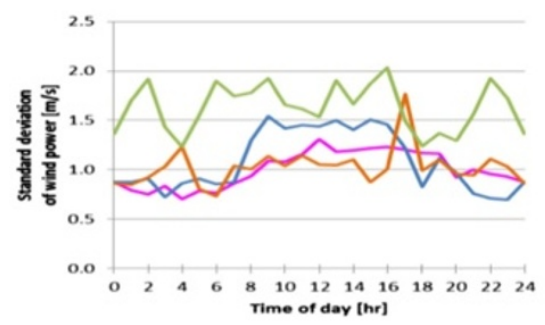

(6) Standard deviation curves of wind velocity

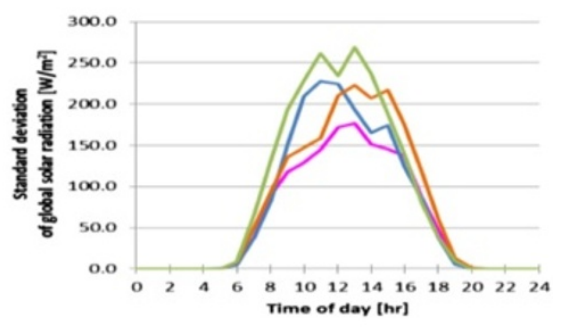

(8) Standard deviation curves of global solar radiation

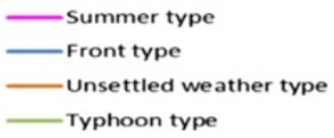

Figure 3 Average curves and standard deviations for air temperature, humidity, wind velocity, and global solar radiation for each pressure pattern. Panels: (1) Average temperature curves for pressure patterns, (2) Standard deviation curves of temperature, (3) Average humidity curves for pressure pattern, (4) Standard deviation curves of humidity, (5) Average wind velocity curves for pressure patterns, (6) Standard deviation curves of wind velocity, (7) Global solar radiation curves for pressure patterns, (8) Standard deviation curves of global solar radiation.

patterns are similar, but high in the typhoon pattern. Global solar radiation in the summer pattern is stronger than in other patterns for all times, and reaches a maximum between 13:00 and 14:00.
Prediction of thermal environment change Averaged time-series data obtained in the previous section cannot be directly applied to days of the same pressure type in summer, because the actual maximum and minimum 


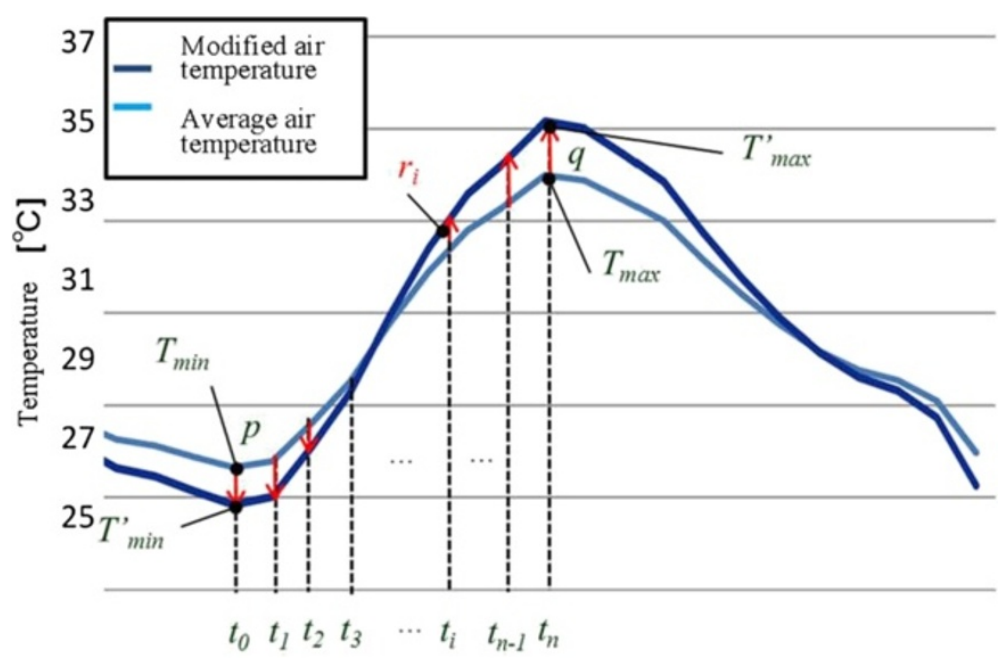

Figure 4 Temperature curve modification.

values usually differ from average values for a given weather forecast. The averaged curves are thus modified, based on the maximum and minimum temperatures provided by the JMA the previous day. Differences between the forecast and average maximum and minimum temperatures, $p$ and $q$, can be computed by Equations (1) and (2), respectively. To modify the average temperature at time $i$, the difference $r_{i}$ can be computed by Equation (3). The time at which the minimum and maximum temperatures are observed is $t_{0}$ and $t_{n}$, respectively. Modified temperature data can thus be obtained as shown in Figure 4.

$$
\begin{aligned}
p & =T^{\prime}{ }_{\text {max }}-T_{\text {max }} \\
q & =T^{\prime}{ }_{\text {max }}-T_{\text {max }} \\
r_{i} & =\frac{p(n-i)+q i}{n}
\end{aligned}
$$

$T^{\prime \prime}{ }_{\text {max }}$ : Maximum temperature predicted by Meteorological Agency $\left[{ }^{\circ} \mathrm{C}\right]$

$T_{\text {max }}$ : Average maximum temperature $\left[{ }^{\circ} \mathrm{C}\right]$

$T^{\prime \prime}{ }_{m i n}$ : Minimum temperature predicted by forecast $\left[{ }^{\circ} \mathrm{C}\right]$

$T_{\text {min }}$ : Average minimum temperature $\left[{ }^{\circ} \mathrm{C}\right]$

$n:$ Time $[-]$

$r_{i}$ : Temperature difference between the average and modified curves at time $i\left[{ }^{\circ} \mathrm{C}\right]$

Since the modified temperature curve has deviations and may have forecast errors, five patterns are generated based on the standard deviation: Extremely high $(+2$ standard deviations), High ( +1 standard deviation), Middle, Low ( -1 standard deviation), and Extremely low ( -2 standard deviations). Figure 5 shows the five temperature change curves.
Thermal environment prediction at and around a construction site Performing CFD analysis using sensor data as input would be ideal for predicting construction site thermal environments, but CFD analysis typically requires from several hours to several days. The proposed method thus performs a number of CFD analyses and insolation simulations for various situations beforehand, and tabulates differences in thermal environment data between benchmark points and other locations in the analysis area as factors. At the construction site, environmental sensors are installed at the benchmark point, and a previous simulation similar to the sensed data is selected. The factors are used to predict the thermal environment data at and around the construction site.

A part of the Suita Campus at Osaka University was selected as an illustrative example of CFD analysis and

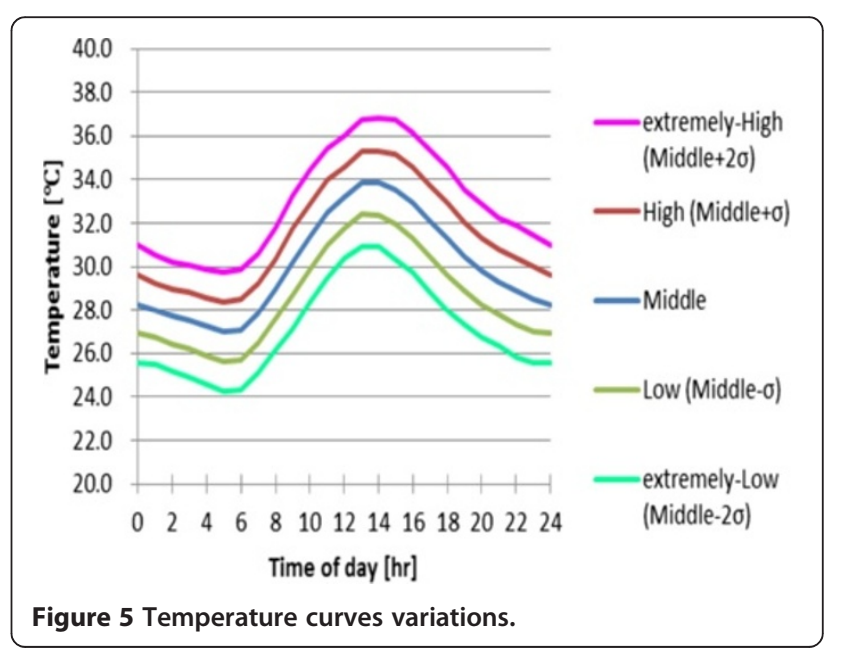


Table 2 CFD analysis conditions

\begin{tabular}{lll}
\hline Pre-processor & Items & Analysis condition \\
\hline Dirichlet & Date & 17 August 2011 \\
Boundary & Time & $9: 00$ \\
Condition & Solar Altitude & 43.81 \\
& Temperature & $30^{\circ} \mathrm{C}$ \\
& Wind Velocity & $4.0 \mathrm{~m} / \mathrm{s}$ \\
& Wind Direction & South \\
& Normal Plane Direct Solar & $400 \mathrm{~W} / \mathrm{m}^{2}$ \\
& Radiation & \\
& Relative Humidity & $50 \%$ \\
& Roughness Class & III \\
Neumann & Inflow and Outflow & Restriction of Re-entry \\
Boundary & Condition of Boundary and & from the Outside of the \\
Condition & Internal Areas & Internal Area \\
& & Restriction of Inflow from \\
& & the Boundary Area \\
\hline
\end{tabular}

insolation simulation. WindPerfectDX was used for the CFD analysis. Table 2 shows a set of sample analysis conditions. Figures 6 and 7 show the results of the CFD analysis. The star in the figures indicates the benchmark point. Colored layers in Figure 6 indicate $t-t_{0}$, the difference between the temperature at the location $(t)$ and that at the benchmark point $\left(t_{0}\right)$. In Figure 7 , colored layers indicate $w / w_{0}$, the ratio of wind velocity at the location $w$ and that at the benchmark point. These factors allow estimation of thermal environment at any location in the analysis area from the sensing data at the benchmark point.

The thermal environment may change significantly due to sudden climate change, thus deviating from the estimated values. In such cases, the system changes the estimated pattern from the initial middle curve to a more appropriate one if the deviation exceeds five minutes. This adaptation mechanism gives the system flexibility under uncertain thermal environments.

\section{Core body temperature prediction system}

The CBTP system predicts the core body temperature of each construction worker, based on the estimated thermal environment data obtained by the TEP system, the worker's physiological data, and planned work site location information. The system then predicts the probable time of heatstroke onset, if heatstroke is anticipated. The risk of heatstroke is very high when the core body temperature reaches $39^{\circ} \mathrm{C}$.

The CBTP system is first initialized with each worker's body temperature, weight, height, and the planned work location for each time span (Figure 8). The system then receives thermal environment data at the construction site, as predicted by the TEP system, and computes core body temperature change according to the thermal environment data and the workers' physiological data.

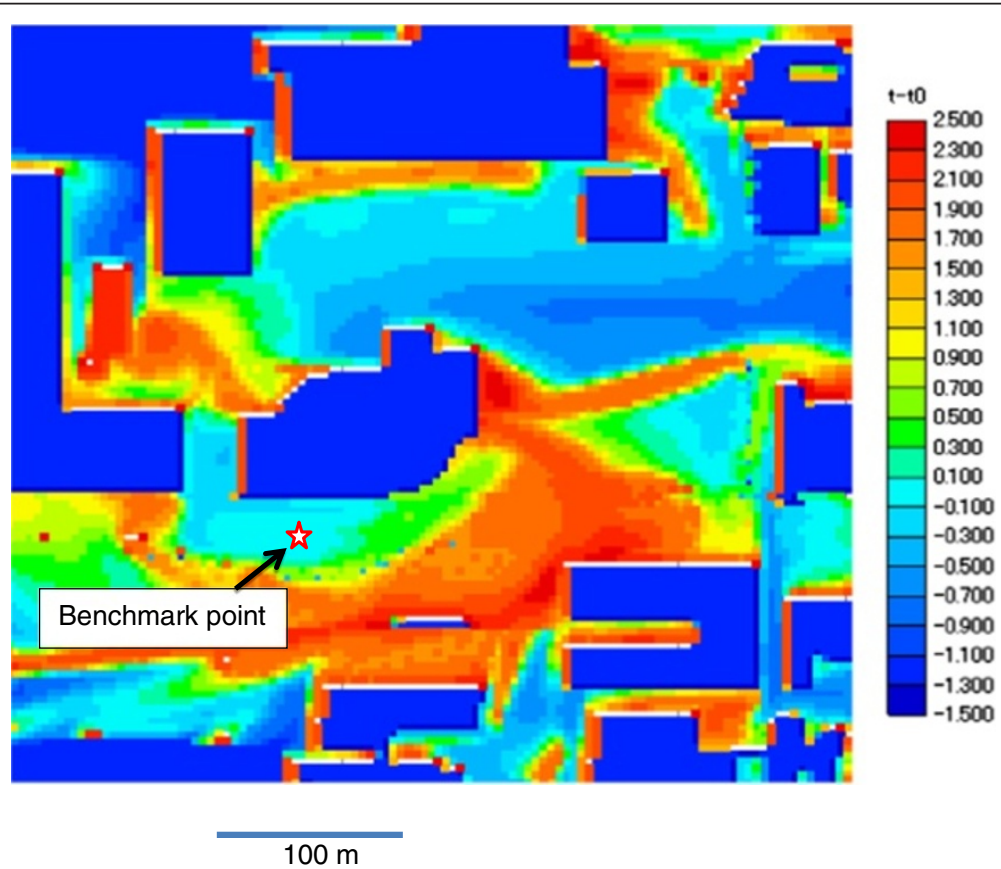

Figure 6 Temperature difference from the benchmark point data, to (t: temperature at a place). 


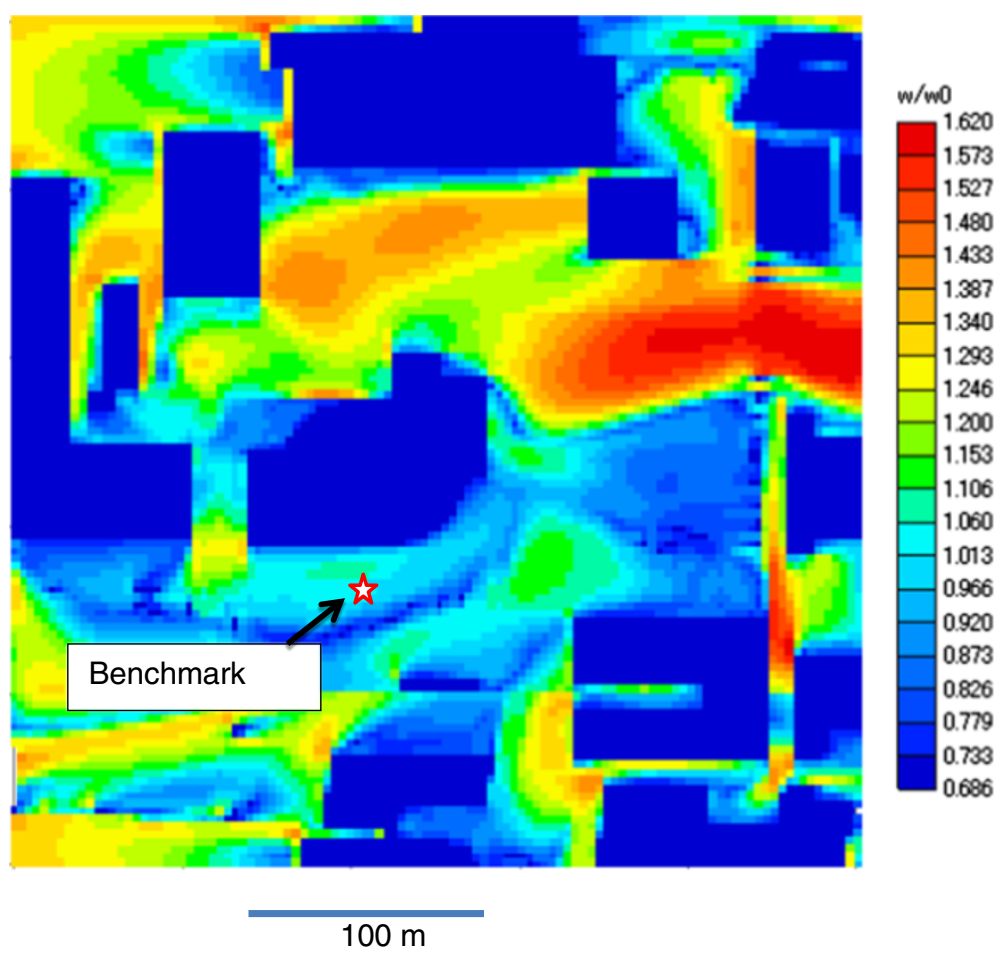

Figure 7 Wind velocity normalized by value at the benchmark point data, w0 (w: wind velocity at a place).

The core body temperature for each worker can be estimated by Equation (4) (Kubota et al. 2003).

$$
\Delta T_{r e}=\frac{5 A_{D}}{4 \times 3.47 \times 10^{3} W_{t}} \int\left(M-W-C_{r e s}-E_{r e s}-C-R-E\right) d t-\frac{1}{4} \Delta T_{s k}
$$

$\Delta$ Tre: Change in body temperature during the day $\left[{ }^{\circ} \mathrm{C}\right]$

$A D$ : Total surface area of body [m2]

$W_{t}$ : Body weight $[\mathrm{kg}]$

M: Metabolism $\left[\mathrm{W} / \mathrm{m}^{2}\right]$ (ASHRAE 2009)

$W$ : External work $\left[\mathrm{W} / \mathrm{m}^{2}\right]$

$C_{\text {res: }}$ : Heat by respiratory convection flow $\left[\mathrm{W} / \mathrm{m}^{2}\right]$

$E_{\text {res }}$ : Respiratory heat of vaporization $\left[\mathrm{W} / \mathrm{m}^{2}\right]$

$C$ : Heat by convection $\left[\mathrm{W} / \mathrm{m}^{2}\right]$

$R$ : Heat by radiation $\left[\mathrm{W} / \mathrm{m}^{2}\right]$

$E$ : Heat by vaporization $\left[\mathrm{W} / \mathrm{m}^{2}\right]$

$\Delta T s k$ : Change in average skin temperature $\left[{ }^{\circ} \mathrm{C}\right]$

These variables are calculated by Equations (5)-(15).

$$
\begin{aligned}
& C_{r e s}=0.0014 \cdot M\left(34-T_{a}\right) \\
& E_{r e s}=0.0023 \cdot M\left(44-P_{a}\right) \\
& C=h_{c}\left(T_{s}-T_{a}\right) \\
& h_{c}=10.4 v_{a}^{0.56} \\
& R=h_{r}\left(T_{s}-T_{r}\right) \\
& \sigma T_{r}^{4}=\frac{1}{2}\left(K \downarrow+L \downarrow+\sigma T_{g}^{4}\right)
\end{aligned}
$$

$$
L \downarrow=(0.526+0.076 \sqrt{f}) \sigma T_{a}^{4}
$$

$E\left(T_{a}\right)=6.11 \cdot 10^{\frac{7.5 T_{a}}{T_{a}+273.3}}$

$$
E=2.2 h_{c} F_{p c l} \omega\left(P_{s k} *-P_{a}\right)
$$

$P_{a}=E\left(T_{a}\right) R H$

$\omega=\frac{A_{W}}{A_{D}}$

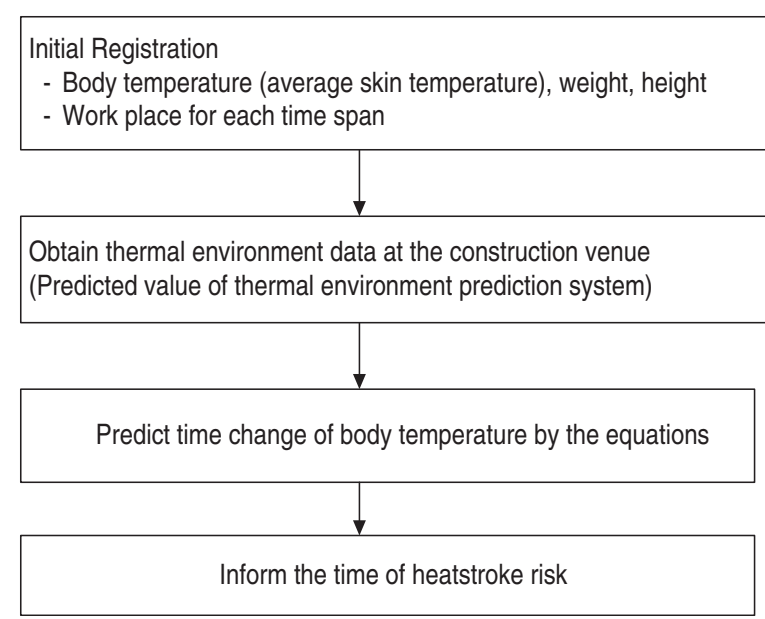

Figure 8 Flow of the CBTP system. 

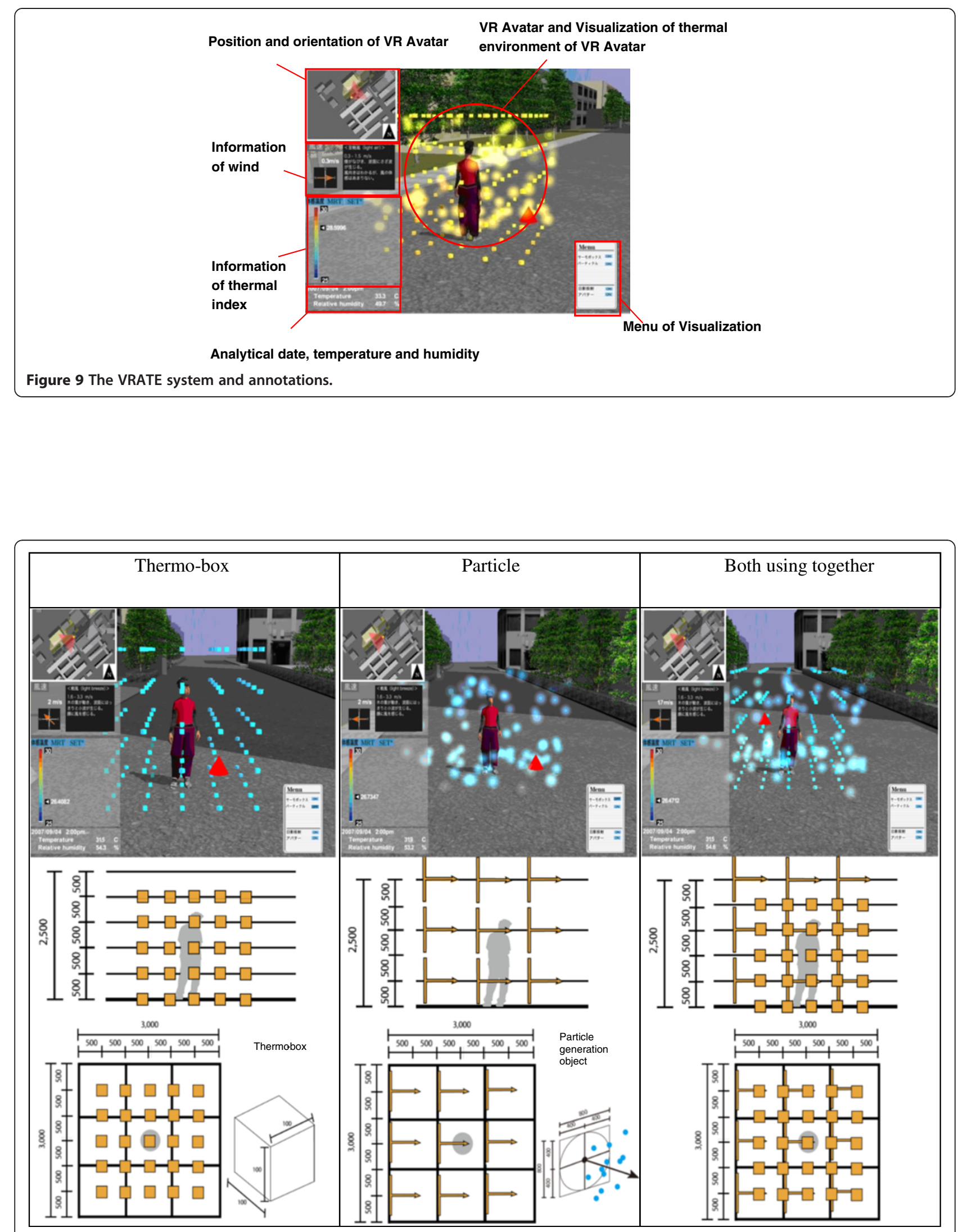

Figure 10 Thermo-box, particle, and combined visualization. 
$h_{c}$ : Convection heat transfer coefficient $\left[\mathrm{W} / \mathrm{m}^{2} / \mathrm{K}\right]$

$v_{a}:$ Wind velocity $[\mathrm{m} / \mathrm{s}]$

$P_{a}$ : Water vapor pressure $[\mathrm{Pa}]$

$T_{s}$ : Average skin temperature $\left[{ }^{\circ} \mathrm{C}\right]$

$T_{a}$ : Air temperature $\left[{ }^{\circ} \mathrm{C}\right]$

$h_{r}$ : Radiation heat transfer coefficient $\left(4.65\left[\mathrm{~W} / \mathrm{m}^{2} / \mathrm{K}\right]\right)$

$T_{r}$ : Average radiation temperature $\left[{ }^{\circ} \mathrm{C}\right]$,

$K \downarrow$ : Amount of global solar radiation $\left[\mathrm{W} / \mathrm{m}^{2}\right]$

$L \downarrow$ : Amount of atmospheric radiation $\left[\mathrm{W} / \mathrm{m}^{2}\right]$,

$T_{g}$ : Ground surface temperature $[\mathrm{K}]$

$f:$ Water vapor pressure $[\mathrm{mmHg}]$

$E\left(T_{a}\right)$ : Amount of saturated water vapor at $\mathrm{T}_{\mathrm{a}}\left[\mathrm{g} / \mathrm{m}^{3}\right]$

$\sigma$ : Stefan-Boltzmann constant $\left(5.67 \times 10^{-8}\left[\mathrm{~W} / \mathrm{m}^{2} / \mathrm{K}^{4}\right]\right)$

RH: Relative humidity [\%]

$F_{p c l}$ : Moisture transmission efficiency of cloth [-]

$P_{s k}{ }^{*}$ : Water vapor partial pressure from skin saturated at skin temperature Tsk $[\mathrm{Pa}]$

$\omega$ : Ratio of wet skin on body [-]

$A_{W:}$ Wet skin area $\left[\mathrm{m}^{2}\right]$

Physiological data such as weight, height, and body temperature for each worker, and planned work schedules including location and job description are input into the system. The TEP system provides the thermal environment data at the work place. Metabolism information for each job, based on a table proposed by ASHRAE (2009), is stored in the CBTP system database. The CBTP system computes worker core body temperatures for each minute, based on initial conditions, and displays the result to the user.

\section{Heatstroke risk notification system}

The heatstroke risk notification system receives worker core body temperature data from the CBTP system. If a worker's core body temperature is predicted to reach $39^{\circ} \mathrm{C}$ at some point in the simulation, the user can be notified of the time of probable heatstroke onset. If heat stroke risk is anticipated, the construction manager should modify the work site and schedule until the risk is eliminated.

\section{Application of the CWHP system}

This chapter demonstrates how the CWHP system can be applied to a construction site.

\section{Application method}

A prototype system was developed based on the proposed methodology, and an experiment was performed at and around the Techno Alliance Building of Osaka University in summer 2011. The software packages 3ds Max (Autodesk) and 3DVIA Virtools 5.0 (Dassault Systèmes) were employed to develop the prototype system. Building construction began in 2010 and completed in April 2011. However, it was hypothetically assumed that the building was still under construction for the experiment. The experiment was performed in a virtual world, in which a realistic construction site on a hot summer day was replicated based on in-situ monitored data.

To virtually replicate the environment we used the Virtual Reality Avatar Thermal Environment (VRATE) system, previously developed by the authors (Onoue et al. 2010). The VRATE system can evaluate a three-

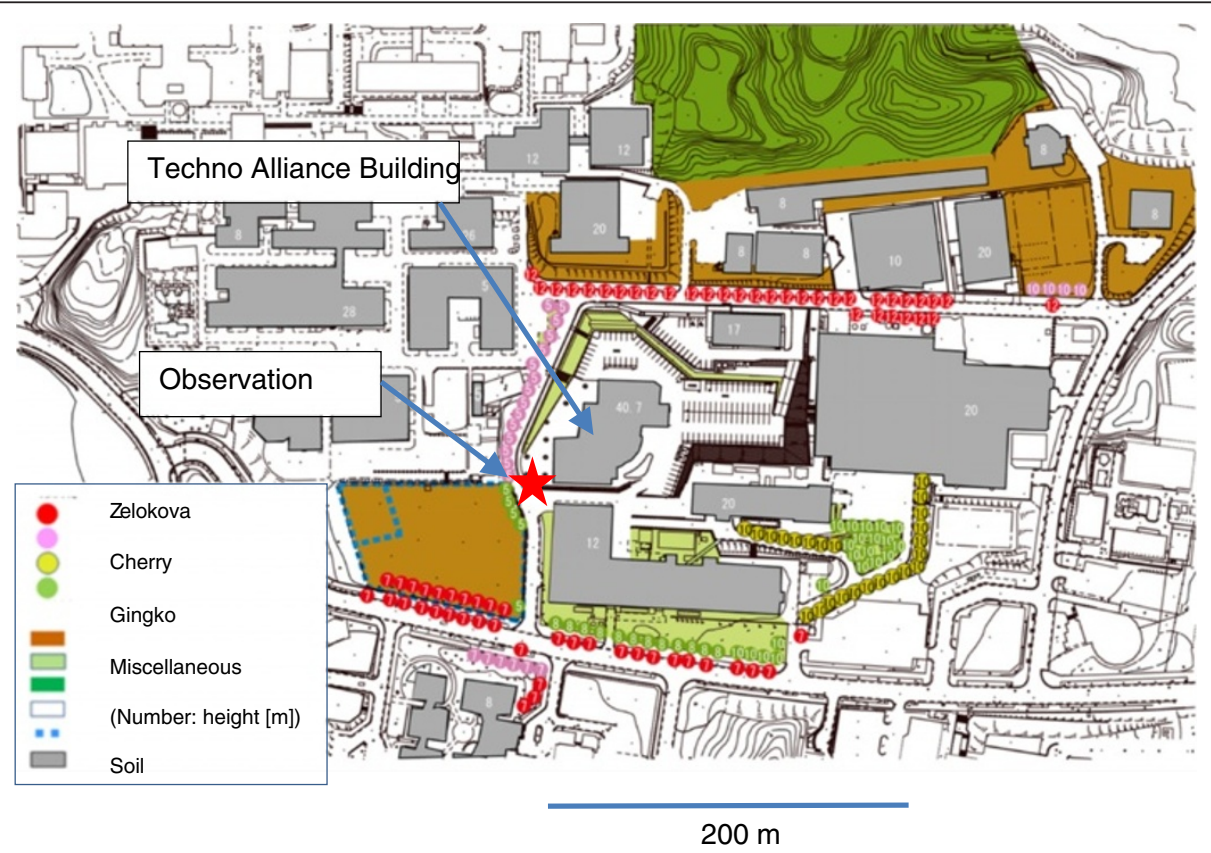

Figure 11 Map of part of the Suita Campus of Osaka University. 


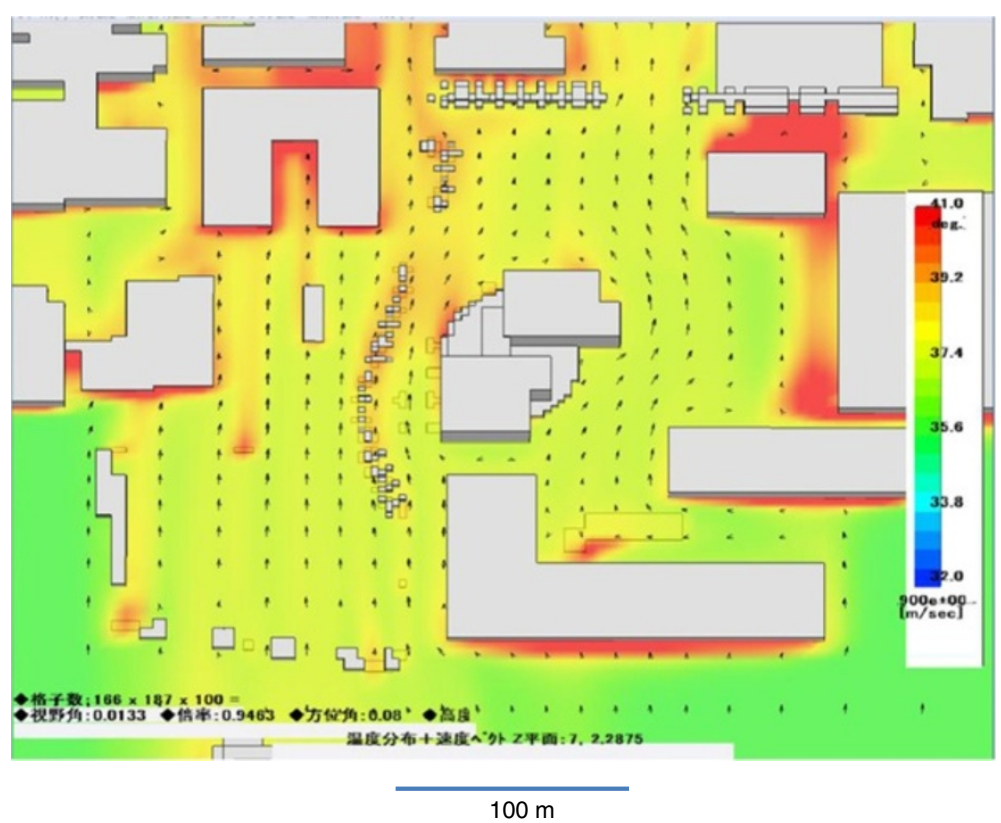

Figure 12 Temperature distribution at height of $1.5 \mathrm{~m}$.

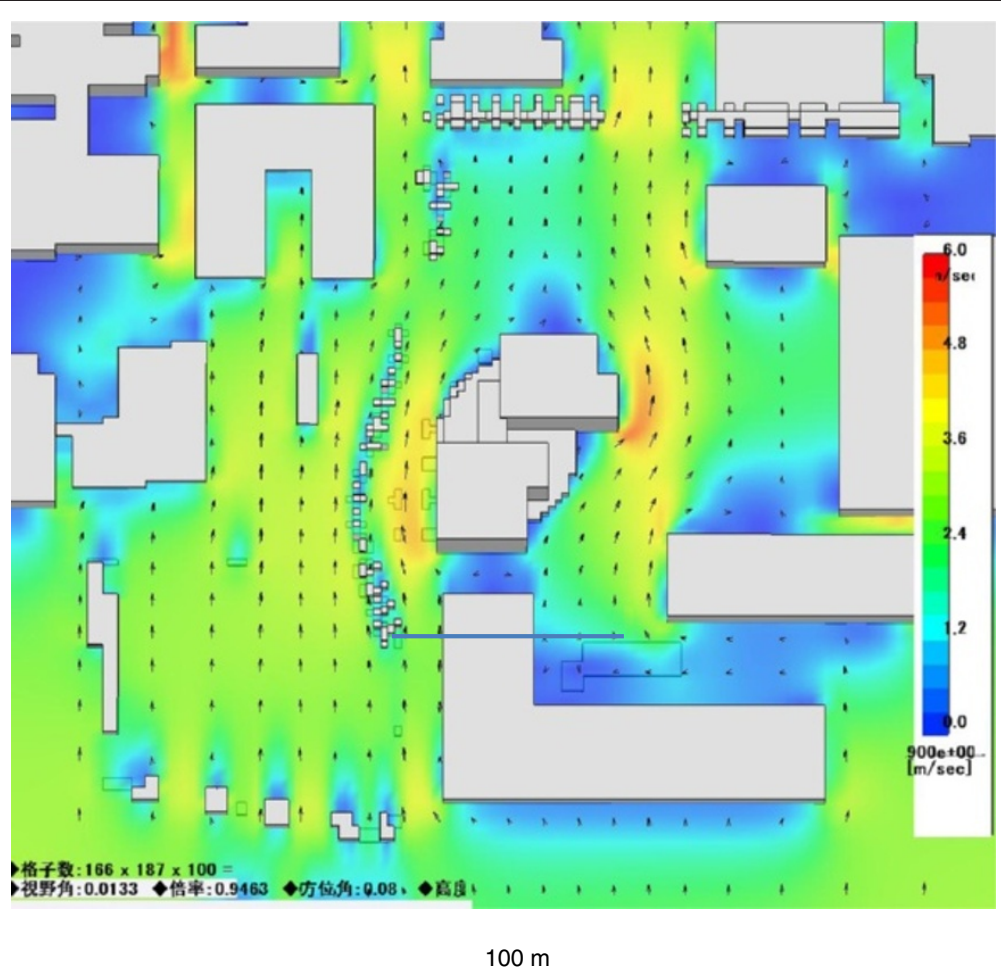

Figure 13 Wind velocity and direction at 12:00 at height of $1.5 \mathrm{~m}$. 


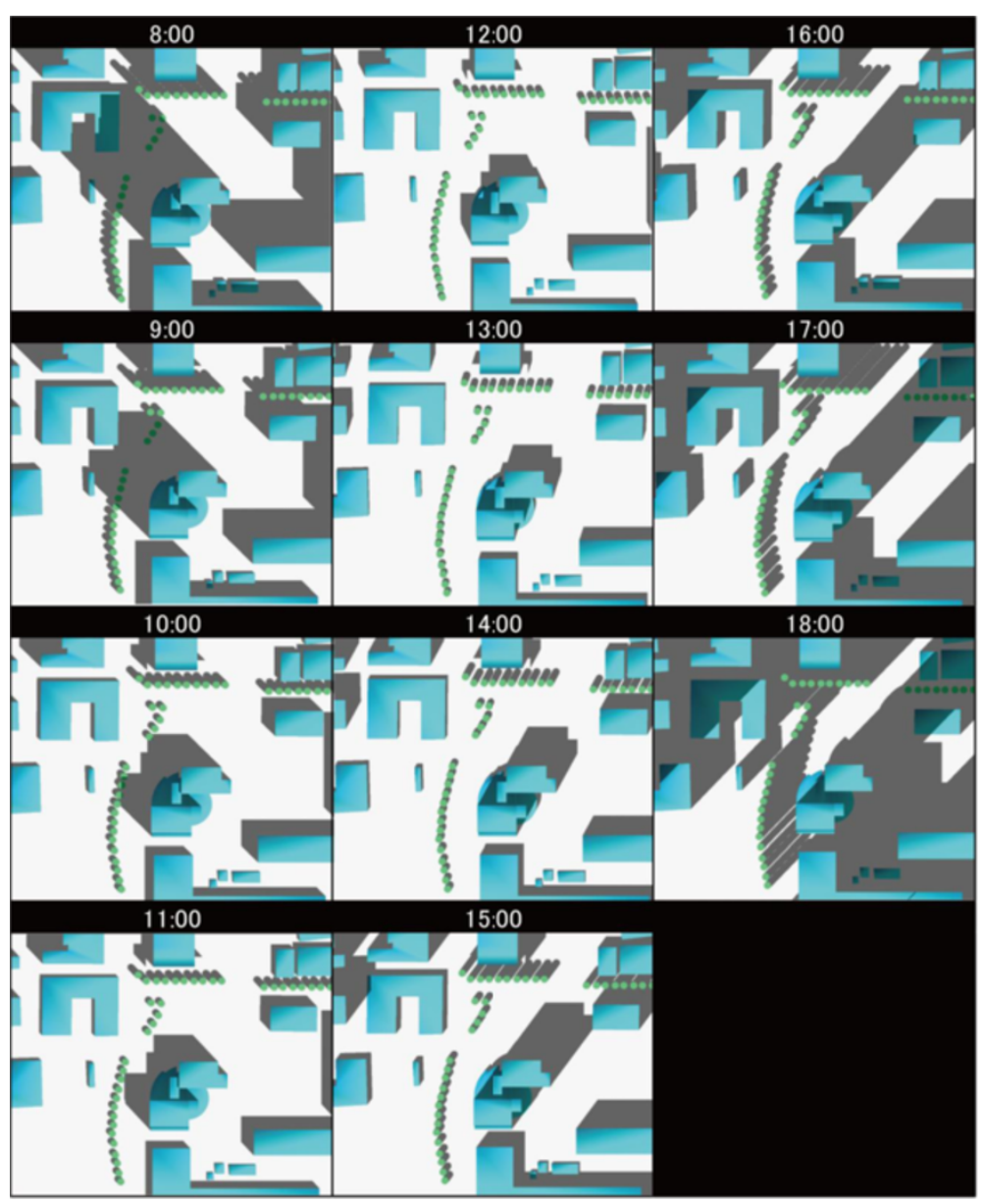

Figure 14 Result of the solar insolation simulations on 17 August 2011.

dimensional virtual thermal environment and can display thermal indices such as sensible temperature (Missenard 1931), MRT, and SET* of the VR avatar, and winds. Figure 9 shows a screenshot of the VRATE system. The menu in the lower right of the screen selects the visualization method as thermo-boxes, particles, or a combination of both (Figure 10). The left column on the screen displays the avatar's position on a map, wind data, thermal index, analysis date, temperature, and humidity. A thermo-box is a $100 \mathrm{~mm}$ cube whose color shows the thermal index value.

Thermo-boxes are centered on the avatar at $500 \mathrm{~mm}$ intervals, and show the thermal environment in a $2,000 \times$
$2,000 \times 2,000 \mathrm{~mm}$ area. Thermo-boxes turn red as the thermal index increases, and blue if the thermal index is low. Particles are small objects generated from a particle generation object based on the avatar's surroundings. The particle generation objects, which are not displayed in the VR space, are arranged at $1,000 \mathrm{~mm}$ intervals in the avatar's surroundings. Particle colors indicate the thermal index in the manner of thermo-boxes, and particle movement shows the wind speed and direction (particles are modeled as very light materials, so wind speed and direction are faithfully reflected). Both methods can be used simultaneously, with thermo-box and particle colors indicating thermal index and particle movement indicating

Table 3 Observation apparatuses

\begin{tabular}{lllll}
\hline Observation item & Apparatus & Range of measurement & Error & Manufacturer \\
\hline Temperature & EcoWizard & $-10-45^{\circ} \mathrm{C}$ & $+/-1.5^{\circ} \mathrm{C}$ & Sumitomo Precision Products Co., Ltd. \\
Relative humidity & EcoWizard & $30-80 \%$ & $+/-10 \%$ & Sumitomo Precision Products Co., Ltd. \\
Solar radiation & Radiation Balance Measurement (CN-11) & $0-2,000 \mathrm{~W} / \mathrm{m}^{2}$ & $+-5 \%$ & EKO Instruments Co., Ltd. \\
Wind velocity & Model 03002 V Wind Sentry & $0.5-60 \mathrm{~m} / \mathrm{s}$ & $+/-0.3 \mathrm{~m} / \mathrm{s}$ & Amalgamated Instrument Co., Pty., Ltd. \\
Wind direction & Model 03003 V Wind Sentry & $0-360^{\circ}$ & $+/-5^{\circ}$ & Amalgamated Instrument Co., Pty., Ltd. \\
\hline
\end{tabular}




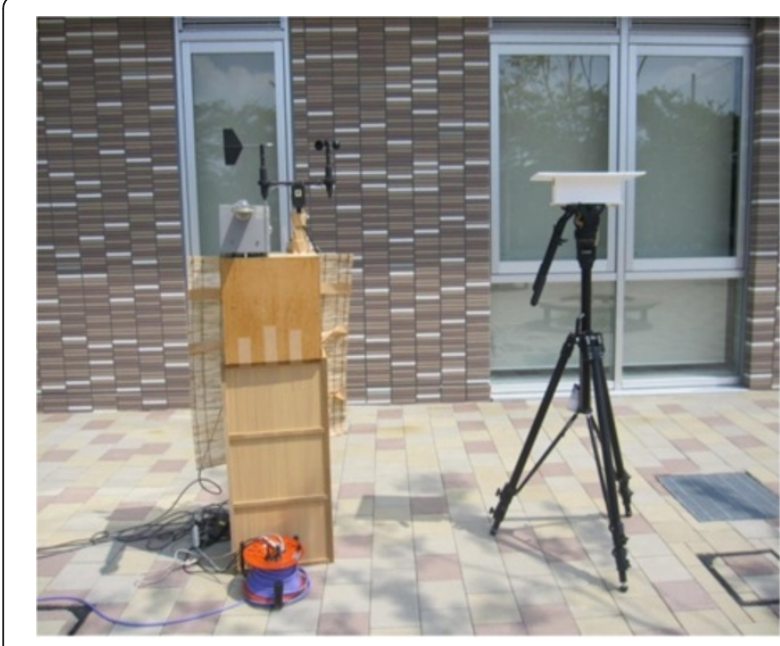

Figure 15 Environmental observation apparatuses. wind speed and direction. The visualization flow is as follows: first, positional coordinates of the avatar and its surroundings are acquired. Next, the nearest positional coordinate is found, and the thermal environment information and thermal index of that coordinate is sampled. In case of a particle, particle generation objects change direction, reflecting wind information. Thermo-box and particle colors are then modified according to thermal index, and a particle is generated from the particle generation object.

\section{CFD analysis and solar insolation simulation}

A part of the Osaka University campus was selected for execution of CFD analysis and insolation simulation to demonstrate the CWHP system. A 3D model of part of the Suita Campus of Osaka University (Figure 11) was created using 3ds Max. 3D model data were used for CFD analysis and solar insolation simulations. Features such as trees, grass, asphalt, soil, and baseball nets were included in the model. WindPerfectDX (Environment Simulation Inc.) was employed for CFD analysis, using the conditions shown in Table 2. Data on reflectivity,

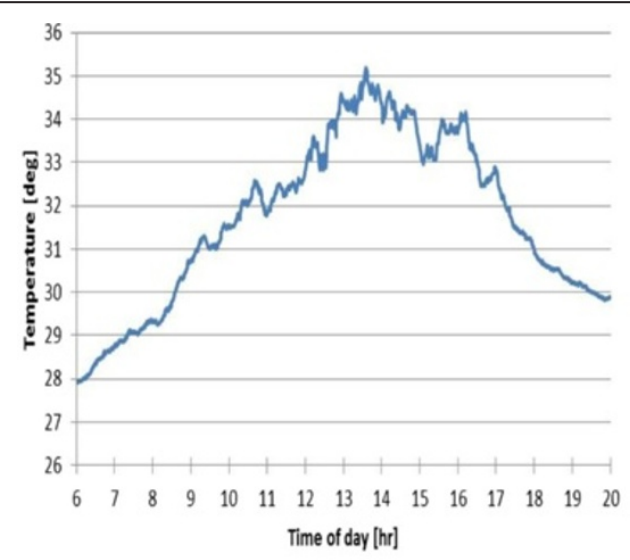

(1) Observed temperature

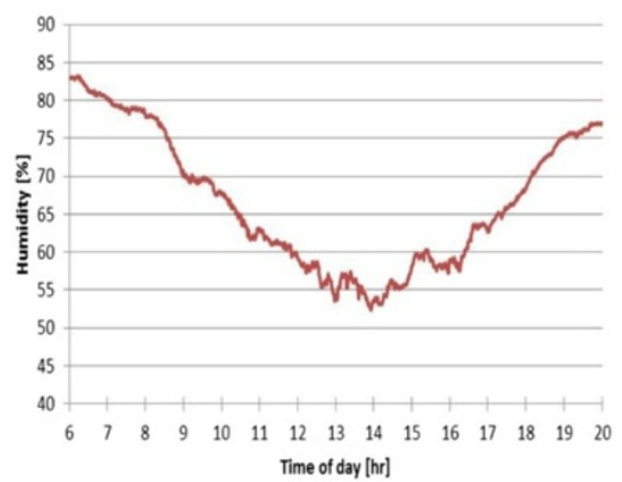

(2) Observed humidity

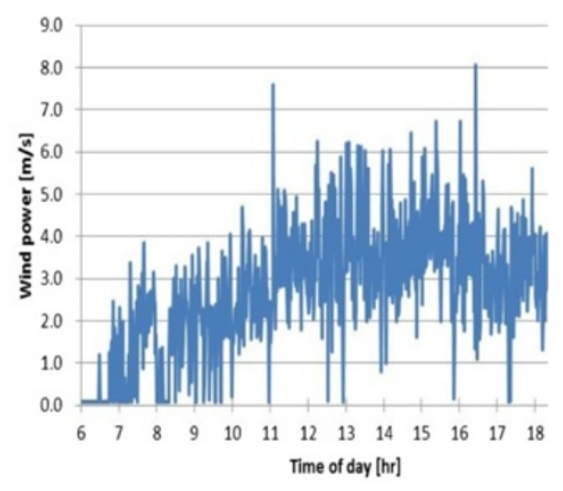

(3)Observed wind velocity

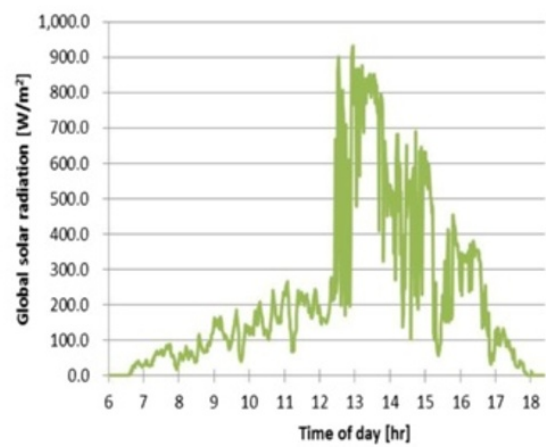

(4) Observed global solar radiation

Figure 16 Air temperature, relative humidity, wind velocity, and global solar radiation observation results. Panels: (1) Observed temperature, (2) Observed humidity, (3) Observed wind velocity, (4) Observed global solar radiation. 
Table 4 Avatar attributes

\begin{tabular}{ll}
\hline Attribute & Value \\
\hline Weight & $60 \mathrm{~kg}$ \\
Height & $1.70 \mathrm{~m}$ \\
Average skin temperature & $36.0^{\circ} \mathrm{C}$ \\
Core Body temperature & $37.0^{\circ} \mathrm{C}$ \\
Amount of perspiration & Computed using the two-node model by \\
& Gagge et al. (1971)
\end{tabular}

density, specific heat, heat conductivity, and transpiration rate of surface objects and plants were taken from a table (ASHRAE 2009) generally used in practice. An area with dimensions $1,150(\mathrm{~W}) \times 1,150(\mathrm{D}) \times 400(\mathrm{H}) \mathrm{m}$ was analyzed. The area of buildings was approximately $600(\mathrm{~W}) \times 600(\mathrm{D}) \times 30(\mathrm{H}) \mathrm{m}$. Gridding for analysis in the densest central area was $3(\mathrm{~W}) \times 3(\mathrm{D}) \times 0.5(\mathrm{H}) \mathrm{m}$. Analysis was executed for 9:00, 12:00, and 15:00 on 17 August 2011. As an illustrative result, Figure 12 shows the temperature distribution at a height of $1.5 \mathrm{~m}$ and Figure 13 shows wind velocity and direction at 12:00. Solar insolation simulation was performed using Virtools. Figure 14 shows the results of the solar insolation simulations for 17 August 2011.
Table 5 A hypothetical construction work order

\begin{tabular}{llll}
\hline Time & Work & Metabolism & Work area \\
\hline 08:00 - 11:00 & Transport building materials & 235 & A \\
11:00 - 12:00 & Check building materials & 90 & A \\
12:00 - 13:00 & Rest & 60 & B \\
13:00 - 18:00 & Scaffolding & 280 & C \\
\hline
\end{tabular}

\section{Observation of thermal environment}

Observation of thermal environment including air temperature, relative humidity, solar radiation, wind velocity, and wind direction was performed from 6 August to 31 August 2011 at a benchmark point (indicated by the red star in Figure 11) near the Techno Alliance Building, which was hypothetically under construction. Table 3 and Figure 15 show the observation apparatuses. Figure 16 shows the results observed on 17 August 2011.

\section{Results and discussion}

Example applications of the CWHP system using the VRATE system

VR Avatar was used to create a virtual construction worker at the building construction site under the

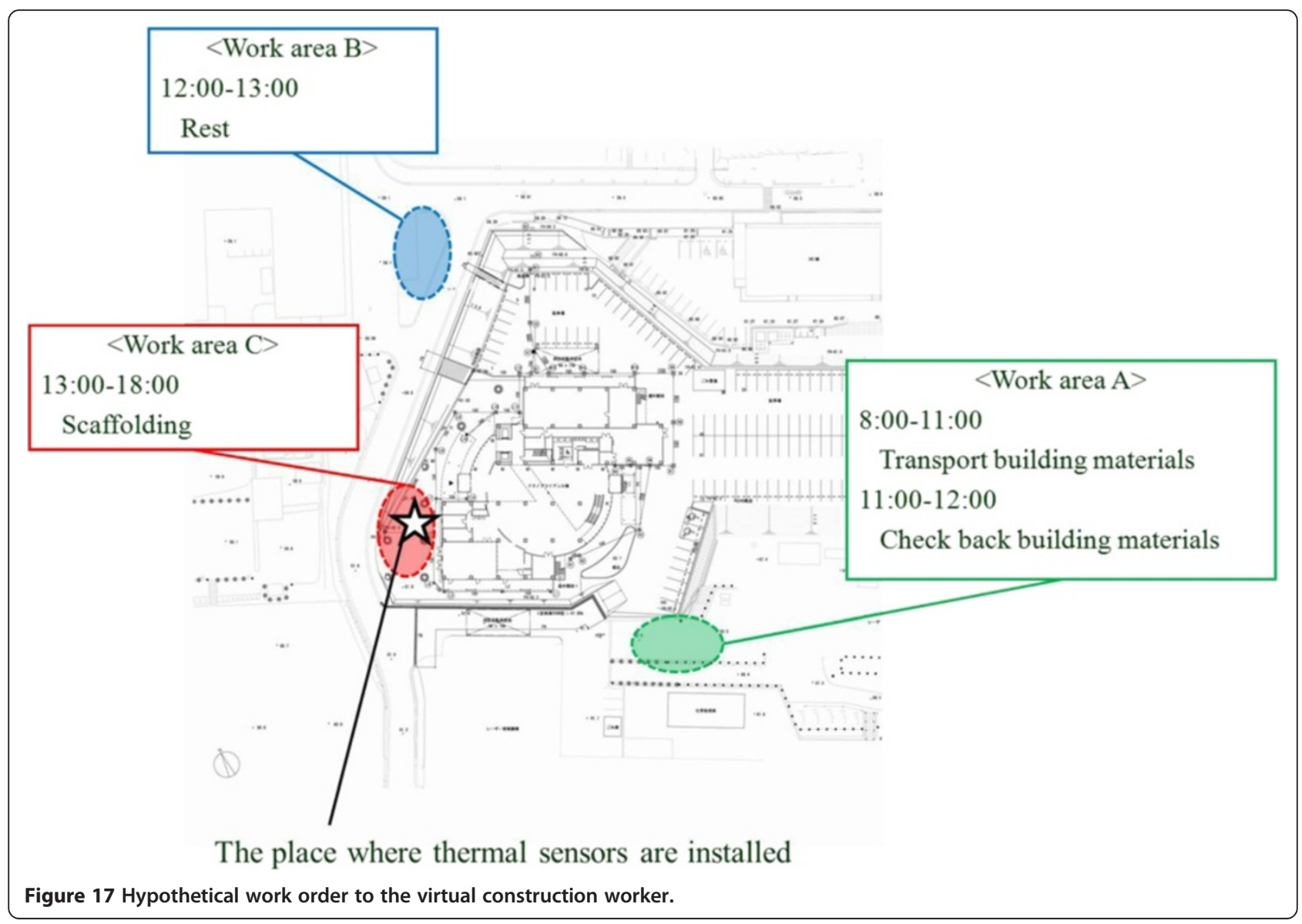


Table 6 A modified hypothetical construction work order

\begin{tabular}{llll}
\hline Time & Work & Metabolism & Work area \\
\hline 08:00 - 09:00 & Transport building materials & 235 & $\mathrm{~A}$ \\
09:00 - 10:00 & Check building materials & 90 & $\mathrm{~A}$ \\
10:00 - 12:00 & Scaffolding & 280 & $\mathrm{C}$ \\
12:00-13:00 & Rest & 60 & $\mathrm{~B}$ \\
13:00-16:00 & Scaffolding & 280 & $\mathrm{C}$ \\
16:00-18:00 & Deterioration survey & 90 & $\mathrm{C}$ \\
\hline
\end{tabular}

Table 7 Another modified hypothetical construction work order

\begin{tabular}{llll}
\hline Time & Work & Metabolism & Work area \\
\hline 08:00 - 11:00 & Transport building materials & 235 & $\mathrm{~A}$ \\
11:00 - 12:00 & Check building materials & 90 & $\mathrm{~A}$ \\
12:00 - 13:00 & Rest & 60 & $\mathrm{~B}$ \\
13:00 - 14:00 & Scaffolding & 280 & $\mathrm{C}$ \\
14:00-16:00 & Deterioration survey & 90 & $\mathrm{C}$ \\
16:00 - 18:00 & Scaffolding & 280 & $\mathrm{C}$ \\
\hline
\end{tabular}

conditions of 17 August 2011, described in the previous section. The avatar was configured as a typical Japanese male, according to the attributes listed in Table 4. A hypothetical construction work order (Figure 17 and Table 5) was assigned to the avatar. From 8:00 to 11:00, the work assignment was transporting building materials, a strenuous task that must be performed in a work area (A) with no shade. From 12:00 to 13:00 the worker ate lunch under the trees in area B. Then, from 13:00 to 18:00 the worker assembled scaffolding at work area $\mathrm{C}$. The avatar moved from area to area according to the work assignment in the VRATE system, and an avatar trajectory record was stored with thermal environment data at the work locations. These data were used in the CWHP system to compute and predict the core body temperature of the virtual construction worker.

The result of the CWHP system application shows that the core body temperature increased about $1^{\circ} \mathrm{C}$ from 8:00 to $12: 00$ by the work of transporting and checking building materials at work area A. During the 12:00 to 13:00 lunch break, core body temperature decreased only slightly. During the afternoon scaffolding work, core body temperature increased about $1^{\circ} \mathrm{C}$ to almost $39^{\circ} \mathrm{C}$ at around $16: 00$, indicating the construction worker might have experienced heatstroke onset at that time.

In the next scenario, in the morning the avatar worked at work area $\mathrm{B}$, transporting and checking building materials as in the previous case, and performed scaffolding work in area $\mathrm{C}$ in the afternoon. Another case variation was also executed in which a sunshade tent was installed at work area A. The result shows as the work area B is in the shade because of trees the temperature there is lower than in work area $\mathrm{A}$, so the core body temperature increased only about $0.5^{\circ} \mathrm{C}$ in the morning. As for the sunshade case, the core body temperature increased about $0.7^{\circ} \mathrm{C}$ in the morning. Both modifications are considered to be effective for mitigating heatstroke risk. However, changing the work areas is more effective in this case because work area B is surrounded by trees and the ground is covered with grass.

Next, the work items and schedule were modified to create the two cases shown in Tables 6 and 7. In the

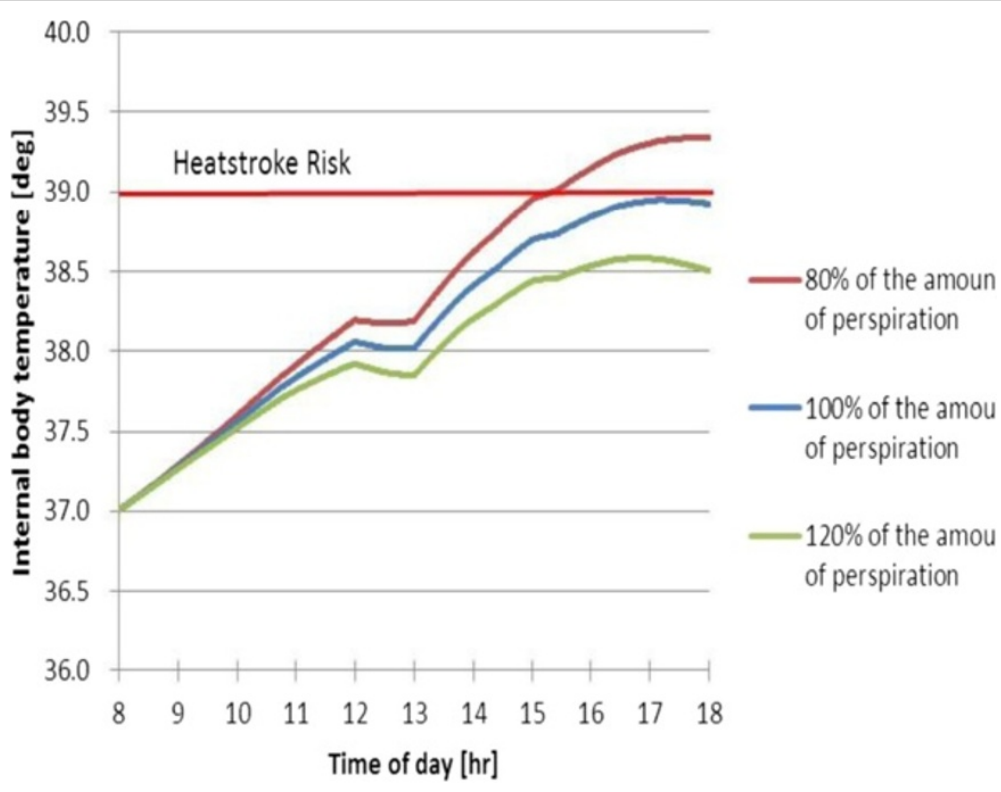

Figure 18 Simulation results for variation in the amount of perspiration. 
Table 6 case the work proceeded faster than in the original case, so from 16:00 to 18:00 the worker performed a deterioration survey with metabolism rating of only 90 (as opposed to scaffolding work, which has a rating of 280) at work area C. In the Table 7 case, the deterioration survey was inserted between 14:00 and 16:00 at work area $\mathrm{C}$. The result shows that the case of Table 7 is better than the other cases from the viewpoint of preventing heatstroke.

The amount of perspiration depends on the person. Individuals who perspire a lot can release heat quickly, so core body temperature increases more slowly than one who perspires less (Gagge et al. 1971). In the following cases, the avatar's perspiration rate varies between 80 and $120 \%$ that of an average individual. Figure 18 shows the results, where the red curve of the $80 \%$ case hits $39^{\circ} \mathrm{C}$ at $15: 00$ and reached $39.3^{\circ} \mathrm{C}$ at $18: 00$, while the green curve of the $120 \%$ case reached a maximum of only $38.6^{\circ} \mathrm{C}$.

\section{Conclusions}

The CWHP system was developed for outdoor construction sites. This system is composed of the TEP system, the CBTP system, and the heatstroke risk notification system. The TEP and CBTP systems were implemented. The TEP system can predict the thermal environment data of all places within the modeled area before work begins in the morning and can flexibly change the predicted data, based on the sensing data at a benchmark point at the site. The CBTP system can predict daily time-series data for construction worker core body temperature, based on the work schedule. We applied the CBTP system to a hypothetical construction site at Osaka University, using the VRATE system and found that this system could predict the core body temperature, which varies throughout the day, and predict the risk of heatstroke according to core body temperature for each time zone. Since the core body temperature changes according to work location, task performed, and individual amounts of perspiration, we confirmed that the evaluation method considers physiological aspects of workers and modification of work schedules.

For future work, a method to convert building information models in and around the site into CFD analysis 3D models should be developed to reduce time and work for making 3D data for CFD analysis. Since in the current TEP system the shaded areas receive no direct solar radiation, partial shading should be incorporated in the future. The heatstroke risk notification system should be implemented using smartphones. If a construction work schedule is changed in the morning because workers receive heatstroke risk warnings, construction managers would want to know how changes will impact the construction job. This could be an interesting research theme, where fourand five-dimensional models (McKinney et al. 1996) could be employed. Finally, the system should be applied to an actual construction site to verify system efficacy.

\section{Competing interests}

The authors declare that they have no competing interests.

\section{Authors' contributions}

NY schemed and directed the research, and wrote most part of this paper. TO implemented and operated the system, and executed the experiment. The article is part of an outcome of the research undertaken by TO as a part of his Master's Thesis. TF and SY are sub supervisors of TO's thesis. All authors read and approved the final manuscript.

\section{Author details}

${ }^{1}$ Division of Sustainable Energy and Environmental Engineering, Osaka University, 2-1 Yamadaoka, Suita 565-0871, Japan. ²Department of Personnel, Nankai Electric Railway Co., Ltd, 2-1-41 Shikitsuhigashi, Naniwa-Ku, Osaka 556-0012, Japan. ${ }^{3}$ Department of Architecture and Civil Engineering, University of Fukui, 3-9-1 Bunkyo, Fukui 910-8507, Japan.

Received: 10 February 2013 Accepted: 10 September 2013

Published: 3 October 2013

\section{References}

Ashie, Y., Tokairin, T., Kono, T., \& Takehashi, K. (2007). Numerical simulation of urban heat island in a ten-kilometer square area of central Tokyo, annual report of the earth simulator center, April 2006 - March 2007 (pp. 45-49). Yokohama, Japan: Earth Simulator Center, Japan Agency for Marine-Earth Science and Technology.

ASHRAE. (2009). ASHRAE handbook - fundamentals (SI). Atlanta, GA, USA: American Society of Heating, Refrigerating and Air-Conditioning Engineers, Inc.

Ashraf, A. S., \& Naseem, M. S. (2003). Worker productivity and occupational health and safety issues in selected industries. Computers \& Industrial Engineering, 45(4), 56-72.

Dang, B., Dowell, C. H., \& Mueller, C. (2006). Heat stress and strain evaluation among aluminum potroom employees. Texas: Health Hazard Evaluation Report HETA 2006-0307-3139, National Institute for Occupational Safety and Health.

Dawood, N., Miller, J., \& Yabuki, N. (2012). Incorporating H\&S into design and construction: the case for integrating serious game engines technologies and $4 D$ planning for collaborative work (Proceedings of the 9th International Conference on Cooperative Design, Visualization, and Engineering, pp. 255-263). Berlin Heidelberg: Springer - Verlag.

Gagge, A. P., Stolwijk, J. A. J., \& Nishi, Y. (1971). An effective temperature scale based on a simple model of human physiological regulatory response. ASHRAE Transactions, 77(1), 247-262.

Hastle, P., Kines, P., \& Andersen, L. P. (2009). Small enterprise owners' accident causation attribution and prevention. Safety Science, 47, 9-19.

Jiang, H., \& Hoyano, A. (2008). A numerical simulation method for analyzing the thermal improvement effect of super-hydrophilic photocatalyst-coated building surfaces with water film on the urban/built environment. Energy and Buildings, 10(6), 968-978.

Kubota, H., Hamada, Y., Nakamura, M., \& Yokoyama, S. (2003). Evaluation of humid-hot working environment. Proceedings of the Seventh International Symposium on Ventilation for Contaminant Control-Ventilation, 2003, 213-218.

McDonald, M. A., Lipscomb, H. J., Bondy, J., \& Glazner, J. (2009). Safety is everyone's job: the key to safety on a large university construction site. Journal of Safety Research, 40, 53-61.

McKinney, K., Kim, J., Fischer, M., et al. (1996). Interactive 4D-CAD (pp. 383-389). New York, NY, USA: Proc. of the Third Congress on Computing in Civil Engineering, ASCE.

Ministry of Health, Labor and Welfare (MHLW). (2011). Press release - number of fatalities due to heatstroke in 2010. Tokyo, Japan: MHLW.

Missenard, A. (1931). Temperature effective d'une atmosphere (Temperature resultant d'un milieu, chauffage et industrie XII (137/138)). 148-153 /491- 498 / 552-557.

National Institute for Occupational Safety and Health (NIOSH). (2010). Protecting yourself from heat stress. Atlanta, GA, USA: DHHS (NIOSH). Publication No. 2010-114.

Occupational Safety and Health Administration (OSHA). (2011). Protecting workers from heat stress. Washington, DC, USA: OSHA. 3154-2011.

Onoue, T., Yabuki, N., Yoshida, S., \& Fukuda, T. (2010). Visualization technique of outdoor thermal environment using a VR avatar (pp. 493-502). Proceedings of 
the 10th International Conference on Construction Applications of Virtual Reality (CONVR).

Paton, N. (2009). OH 'problem' for construction. Occupational Health, 61(8), 6.

Sacks, R., Rosenfeld, O., \& Rosenfeld, Y. (2009). Spatial and temporal exposure to safety hazards in construction. Journal of Construction Engineering and Management, 135(8), 726-736.

Tien, Z., Zhu, N., Zheng, G., \& Wei, H. (2011). Experimental study on physiological and psychological effects of heat acclimatization in extreme hot environments. Building and Environment, 46(10), 2033-2041.

Yi, W., \& Chan, A. P. C. (2013). Optimizing work-rest schedule for construction rebar workers in hot and humid environment. Building and Environment, 61, 103-113.

Zhang, S., Teizer, J., Lee, J.-K., Eastman, C., \& Venugopal, M. (2013). Building information modeling (BIM) and safety: automatic safety checking of construction models and schedules. Automation in Construction, Special Issue Spatial Design Assistance, 29, 183-195.

doi:10.1186/2213-7459-1-11

Cite this article as: Yabuki et al:: A heatstroke prediction and prevention system for outdoor construction workers. Visualization in Engineering 2013 1:11.

\section{Submit your manuscript to a SpringerOpen ${ }^{\circ}$} journal and benefit from:

- Convenient online submission

- Rigorous peer review

- Immediate publication on acceptance

- Open access: articles freely available online

- High visibility within the field

- Retaining the copyright to your article

Submit your next manuscript at $\gg$ springeropen.com 